\title{
Stylistic Analysis of Igbo 'Laja Terracotta Sculptures of Owo
}

\author{
Adémúlèyá, Babásèhìndé A. Ph. D \\ Department of Fine and Applied Arts, Obafemi Awolowo University, Ile-Ife \\ sehindeademuleya@oauife.edu.ng, babaleya@yahoo.com
}

Doi:10.5901/mjss.2015.v6n4s2p216

\begin{abstract}
This study is an attempt at identifying the stylistic variables as evident in the treatment of forms and features of the Owo terracotta sculptures with a view to determining sameness and differences (of hands) in the production of the sculptures. Efforts made so far have basically identified either, features that can be linked with styles of other art traditions (of Ife and Benin) in the sculptures or those characteristic features that differentiate Owo terracotta arts from these traditions using the "group theory". This study focussed mainly on the distinctive traits that are indeed peculiar to Owo and cannot be found even in the neighbouring art traditions. Data were collected from primary and secondary sources with the study relying heavily on primary sources of data. Critical observation of the sculptures were made for proper formal analysis while heads and fragments of heads were purposively selected for a meaningful stylistic analysis, since the available heads and assembled head fragments do not merge appropriately with the headless bodies and other assembled fragments. Interviews were also conducted with the head of the local artists' guild in Owo. The secondary sources provided information on previous studies on art traditions acclaimed as having noticeable stylistic similarities to the Owo terracotta sculptures (i.e. Ife and Benin). The paper posits that, despite the diversity of styles or sub-styles in the sculptures, they generally depict mood and movement, a trait found to be distinctive of Owo terracotta sculptures.
\end{abstract}

Keywords: Benin, Group-theory, Igbo'laja, Ife, Iregun, Owo, Sculpture, Terracotta

\section{Introduction}

Owo is a Yoruba town situated south west of Ile-Ife, the traditional origin of the Yoruba. The town is said to be a conglomeration of peoples from diverse places which comprises the indigenous Efene people; the lloros and their ruler who was the ancestor of the Olowo, as well as later refugees and immigrants from neighbouring towns and kingdoms. It is located approximately midway between lle-Ife and Benin City.

In its present position, it is only about one hundred and ten kilometres north of Benin (Eyo 1976: 38) and more than any other Yoruba town closely related to Benin culturally and linguistically (Fatunsin 1992: 94). These influences are evident in architecture, royal regalia as well as many chieftaincy titles and place names. Added to this, is the forms and concepts of Owo ivory and wood sculptures which display some elements of Benin influences. On the other hand, the origin of the ancestors of Owo people and that of the founder of the present dynasty in Benin are linked to lle-Ife in oral tradition (Adepegba 1995: 22). In certain quarters, the two are even believed to be brothers and of the same mother (Asara 1975).

Owo terracotta sculptures are the finds of the three excavations carried out at two sites in Owo town. Ekpo Eyo carried out the first excavation in 1971 at a place called Igbo'laja (Eyo, 1976:38), while Anthonia Fatunsin made a re-visit of the Igbo'laja area in 1981and also excavated a new site at Iregun Street in ljebu-Owo at the same period (Fatunsin, 1992:94). Igbo'laja and Iregun quarters are about four kilometres apart within Owo town.

While the three excavations (of the two sites) have yielded very rich terracotta manufacture of portraitures, human and animal figures, objects suspected to be sacrificial and of gruesome subjects (Fatunsin, 1992:94) and several fragments of figures that are worthy of study, the attention in this paper shall be on the Igbo'laja sculptures. They were mostly found in their fragmentary state of which some have been re-assembled to assume their original forms. The total objects and fragments of objects are well over eighty. They are rendered mostly in naturalistic form. "Concentration one" of the 1971 Igbo'laja site which yielded the largest number of the total finds has been dated 1435 AD by Eyo (1976:38).

Apart from placing, conveniently, the name of the town on the list of important ancient civilizations in Nigeria, the terracotta sculptures of which some are of human figures that display features similar to those of Ife and Benin arts (Eyo 1977:126), have equally turned out to be the long awaited "missing link" in the hands of historians and researchers "to fill in the gap" in their various attempts, either to construct historical and artistic continuum of the traditions mentioned or as 
concrete evidence in establishing further, the long proposed assumption of Owo as having a strong independent style (Gillon, 1984).

For researchers and art historians who are in want of evidence to either establish the theory of Owo art as an independent art style or in proposing the existence of a continuum of art tradition or linear descent from lfe to Benin, the discovery of terracotta sculptures in Owo which display Ife and Benin characteristics became a handy tool which fits well into the dotted lines of their theories. According to Gillon (ibid), this attempt was first made during the exhibition organized by the Royal Anthropological Institute in 1949, and later in another exhibition "Traditional Art from the Colonies" in 1951 in London. Art objects exhibited at these exhibitions, showing both Edo and Yoruba characteristics were attributed to Owo.

Worthy of mention in this direction was the leading role played by Fagg (1951 and 1953). He started the process of disengaging ivories suspected to be of Owo origin from those of Benin in 1951. And ever since, scholars have been postulating theories and adapting criteria in sorting art objects that are neither Edo nor Ife styles, nor works that are not showing traces of the two art traditions which Fraser (1975:23) refers to as "art that has Benin-like iconography without being specifically Benin style.

In attributing art objects with both Edo and Yoruba characteristic to Owo, perhaps the geographical placement of Owo town has often been considered a strong factor. According to Poynor (1976:40) "its position on the far eastern edge of Yoruba land makes it transitional between Yoruba-speaking people to the west and Edo-speaking peoples to the east". In this position, it is not surprising that the few available literature on the subject of this study tend to focus mainly on comparative stylistic analysis that illuminate form and significance of the Owo terracotta sculptures in terms of their relationship (affinities) with Ife and Benin art traditions. Nothing has so far been said about the indigenous Owo style in neither the terracotta sculptures nor the individual creativity of the artists.

Based on archaeological and ethnological evidences, Ekpo Eyo who conducted the Igbo'laja excavation commenced the process of stylistic analysis of the finds by classifying the objects into three broad "group styles". Those objects which bear "Ife characteristic features" were labelled "Ife style", while objects with "adopted Benin concept" were tagged "Benin style". Those objects that bear affinity with neither of the two styles, he claimed were the real Owo style. As he puts it "... for the sake of convenience, those objects whose style conforms to neither the Ife nor the Benin style are regarded as Owo style" (Eyo (1977:128).

In his analysis Eyo simply focuses on basic similarities and ignores the significant differences that are easily discovered when one compares the various known pieces of a given class of objects found in such a restricted area. Biebuyck (1969:11) has however warned against such approach, he noted that art forms must not be taken at their face value. Surprisingly, scholars who have written on Owo terracotta sculptures seem not to have been bothered with the issue of Owo stylistic peculiarity and of individual stylistic variations of the objects. They seem to be satisfied with Eyo's model of classification of the sculptures into what Biebuyck (1969:8) referred to as the "so-called homogenous styles and sub styles with the distribution of motifs"

Adepegba (1995: 18) also indicates the Ife - Benin influence but notes the under-current of their neighbouring cultures. He however concentrates on comparative analysis of iconographic features, offering possible significances of such in relation to other art traditions. There are some scholars who however acknowledged the presence of certain characteristics that are believed to be peculiar to Owo terracotta sculptures. Gillon (1984) notes with reference to Ife and Benin art styles that the Owo terracottas "... are also proofs of Owo's individual character, since they are more vital and vigorous than the art from others". Gillon however did not expatriate further on this so - called "Owo's individual character".

Fatunsin (1992) who conducted the last two excavations goes a bit further by describing some features she considered to be distinctive of Owo terracotta sculptures - i.e. "eyes without pupils, "broad mouth with very thin upper lip" and "very flat nose with wide nostrils" - she also described all the finds in broad terms as either of naturalistic or abstract traditions (Fatunsin 1992:96). The only notable stylistic study of the Owo terracotta sculpture was done by Abiodun (1989) who introduced the term "Owo arts." His analysis however centres on pin-pointing the differences between Owo and Ife characteristic features. He left his use of the term "Owo arts" undefined and treated it in a nonspecific term (Abiodun 1989: 103). He sees the works as if produced by one single artist.

Like Gillon and Fatunsin, Abiodun also treated the Owo terracotta sculptures as a group art or a collective style with no attempt to identifying the peculiar 'hands' of the artists in the group nor pin-point Owo traits in other works that are not of "Ife style". No matter what, even if there existed a common group or workshop, there should be, as Sieber (1969:198) rightly noted some "degrees of leadership (and ability)". It is therefore clear that the issue of stylistic possibilities in Owo terracotta sculptures is yet to be addressed. Efforts made so far have only identified those features that can be linked with styles of other art traditions in the sculptures or those characteristics features that differentiate 
Owo terracotta arts from those of the neighbouring traditions using the "group theory" which as rightly noted by Sieber "would act to block the search for individual characteristic" (ibid). It is here opined that an investigation of the individual styles of the artists or schools involved in the production of the Owo terracotta art is of great impotence and necessary for a better understanding of the sculptures. This will definitely unmask the distinctive Owo characteristic in all the available pieces.

Such an effort is indeed not new in the study of art works (especially the antique cultures - art) found in a restricted area and within a closely knit cultural entity. Scholars like William Fagg (1969) had worked on Benin plague; Adepegba (1978 \& 1995) on Nok terracotta sculptures; Pogoson (1984) on Essie stone images; and Eyefoki (1991) on Ekpu status of Oron. The results of these studies further revealed the immanent qualities of the works and their makers, thereby enriching our understanding and appreciation of the uniqueness and belongingness to group of the works. From mere observation, all Owo terracotta sculptures (though few), could not have been made by a single artist or from a single workshop. In support of this view is Ogunleye's ${ }^{1}$ remark on how Olowo on throne at any point in time used to acquire works of art from different artists in the past. He informed that though there was no established guild of artists in Owo in remembered times; he recalled that his father told him of how one Oshogho from whom his family descended was the appointed representative of brass/blacksmiths to the ruler. Whenever the Olowo needed an art work, Oshogho would summon other brass/blacksmiths to come with works of required descriptions from which he would select the best for the Oba.

For a proper examination, and to firmly establish Owo indigenous traits in of the Igbo'laja terracotta these selected works, references are also made to some typical sculptures (similar to Owo examples i.e. Ife and Benin) of those art traditions acclaimed as having noticeable stylistic similarities to the Owo terracotta sculptures (i.e. Ife and Benin).

\section{Stylistic Analysis of the Terracotta Sculptures}

The main distinguishing feature of the style of the Igbo'laja sculptures is its naturalistic tendency. They are few in number and they were found smashed and scattered in no order, all-together on the same layer, a situation which Eyo (1977:126) suspected must have been caused by the collapse of a mud hut originally sheltering the sculptures. Although they are made up of head fragments, headless bodies and body fragments of human and animal representations, only the heads and head fragments and some of the animal representations are here sampled for analysis. Most of the body fragments could not be assembled for a meaningful analysis.

It needs be recognised as noted by scholars and acknowledged earlier in this study, that the terracotta sculptures of the two groups of terracottas of Igbo'laja have strong stylistic affinities with the arts of Ife and to some extent Benin. This is evident in certain iconographic features common to Owo terracotta sculptures and these two artistic traditions. Examples of these are in animals such as leopard, cock, rat, lizard etc. as well as in the face marking patterns depicted i.e. the parallel vertical striation, the three cat whisker marks and the four vertical short lines above the eye brow. Many of the terracotta sculptures also exhibit certain stylistic features that resemble those of the two art traditions. But an overwhelming Ife connection is quite noticeable. There also exist in Owo terracotta sculptures certain characteristics that are indeed indigenous to Owo.

The search for Owo distinctive traits and variables in the Igbo'laja terracotta sculptures have been based strictly on the treatment of forms and not on motifs or themes. Sameness in beliefs commonly shared by different people living close to one another or in the same region which serve as basis to what is mostly represented often provides common themes that may be represented in their individual ways. The use of such ethnographic materials in stylistic analysis will only continue to block a true search for individual characteristic trait(s) of a particular art centre. The fact that leopard for instance is represented in Benin, Igbo Ukwu or Ife as well as in Owo does not in any way imply "sameness: in style or a stylistic diffusion. It has been discovered that the structure, form and features of the animal are not treated in the same manner in all the art centres. It is the peculiar manner in which themes are depicted that can reveal differences or sameness in styles. The focus of this analysis therefore are the ways and manners in which the forms and features of the images are rendered.

A look at the heads and head fragments indicates some differences in their basic structure and the treatment of form. Some of the heads are rendered with noticeable attempt at extreme naturalistic idealization while some are less naturalistic. A keen look at the heads in idealized naturalistic style further reveals some important differences in the treatment of certain features, especially in the definition of the eye and its borders (the lids and lashes) and the treatment of nose and mouth. They suggest that the sculptures are not of the same hand (style), in the first sub-style, noticeable attempt is made at depicting features in details. This sub-style which also has the largest number of heads and head fragments, coincidentally are those with some characteristic features similar to Ife tradition. The head recovered from the 
Alaja priest Plate 1) so much resembles Ife terracotta (Plate 2) in its treatment of form and features to a degree that suggests that one derived from the other. Both heads reflect the under structure of cheek and jaw bone as if modelled directly on skull. The forms are however more pronounced in the Owo head. The head (Plate 1) and others of the substyle also resemble some Ife examples (Plates 3 and 5 ) in their treatment of eye balls which is without pupils and to some extent in the definition of the eye border as well as the mouth.

However, despite the similarities or stylistic relationship as evident in the treatment of heads of this sub-style and those of Ife, a further comparison of the head and the generality of Ife pieces reveal some glaring differences which distinguish the Owo from Ife. The peculiar roundness of Owo heads differs to the typical oval shapes of Ife pieces. The overall treatment of Owo heads is less delicate and not as detailed as those of Ife. Although there is a noticeable resemblance in the shape of the eye-rounded under an overlay of eyelids above and below of which Adepegba (1984:6) noted to be a particular feature common to all the arts of south-western Nigeria. The eyes in the Owo heads (as different to those of Ife) are wide apart and which make them appear smaller. The overlay eyelids also differ slightly, they are more sensitively modelled and more pronounced in Owo. The nose in Owo head is wider and flatter. Although the upper lip in both (Ife and Owo) are bow-like, it is more curved in Owo, with both edges tucked into the cheek thereby emphasizing a gentle smile which goes along with the sensitive gaze of the eyes (Plates 3 and 5). This unique depiction of the emotional state is absent in Ife heads. Instead, it is the uniform calm, unruffled and expression-less look that characterizes lfe style. The happy mood depicted in Owo head in Plate 3 is also extended to the action displayed by the remaining part of the body. They both suggest an intentional portrayal of emotion. This particular trait is indigenous to Owo and is not seen in Ife (Plate 4).

The head fragment in Plate 6 differs from the above discussed sub-style. This sub-style is characterized by its wide and enlarged eye and its thick upper eye lid without eye lash. The fragment and others with the same features have vertical short marks above their eye brow. These marks and the presence of leopard among the represented animals of Owo terracotta sculptures, supposedly have led to Eyo's (1976:38) reference to the heads of the sub-style as having "adopted Benin concept" and probably informed his classifying them as "Benin style". It becomes necessary to note here that the relationship between the fragment heads of this sub-style together with the leopard and Benin art is cultural and not of stylistic import. Compared with the Benin head in Plate 7, it becomes obvious that there is little or no stylistic relationship between the Owo head fragments and the Benin example. The little resemblance seems to be only in the definition of the nose wing. The eye ball and the definition of the eye border differ greatly. The curved upper eyelid of the Owo head is modelled thick and seem swollen, the slightly curve (thin) lower lid is tucked into the exposed end of the upper lid, a characteristic that is equally identified (though in varying degree) with the first sub-style.

The eye lids in Benin head (see plate 7) are almost of the same thickness and same curviness. They are joined at both ends giving an almond shaped ring round the eye ball. Unlike in Owo, the eye balls of Benin head are with inlaid pupils. The pupil-less eye ball of Owo head is stretched from the nose bridge to the edge of the face, making it wider and larger than normal. The angle of the eye (palpebral ligament) is slightly buried under the wide humped nose bridge and unlike in the Benin style, the humped nose levels-up with the fore head. This characteristic feature is peculiar to this Owo sub-style and not found in Benin. It is quite a distinctive Owo trait. Although the missing parts of the fragments denied one of telling the emotional content of the heads, the feeling around the nose and the eyes in Plate 6 suggest certain hardness. The fragment and others of same features are rendered almost in the same manner which suggests their having been made by the same hand, an Owo artist possibly depicting a Benin person.

The heads in Plates 8 and 9 are quite different in style. Their naturalistic styles are in varying degrees. Although they have some unifying characteristics which placed them in the stream of already identified Owo traits, their differences which probably suggest their being products of different hands do not permit lumping them together as a sub-style. Plate 8 displays a good attempt at rendering the face structure in a more balanced manner. The head maintains the roundness of form typical of Owo heads. The eye and eye borders (though a bit slant) are depicted with the lower eye lid tucked into both ends of the thicker upper eye lid. Plate 9 is not as naturalistic as 8, some of its features are slightly stylized but the eye and the eye borders are treated in almost the same manner as that of 8 . The two heads share some semblance with some of the decapitated heads in the basket (Plate 10). The eye and the eye border in some of the heads are also treated with the lower eye lid tucked into both ends of the thicker upper eye lid. More importantly, the heads in the three Plates parade dramatic emotional feelings. Plates 8 and 9 are tensed as noticeable in their large protuberant eyes. Plate 9 depicts discontentment and a sort of uneasiness within, while Plate 8 is depicted with its slightly twisted tongue forcefully thrusting out of the tightly held lips. The artist of Plate 10 added more drama into one of the heads in the basket by depicting its mouth gapped as if expressing anguish or agony.

With the above analyses of styles of the Igbo'laja sub-group which is characterized by its naturalistic tendency, two distinctive sub-styles have emerged. The first is characterized by its tendency toward extreme naturalism, and the other 
characterized by its idealized wide and enlarge eye with its thick upper eye lid without eye lash. In all, there is a noticeable degree of sameness in the treatment of the eye and the eye-border in which the lower lid is tucked in at both ends of the thick and arched upper lid. This characteristic feature cuts across all the naturalistic terracotta heads of this sub-group and not peculiar to human heads, but depicted in the same way in animals. A comparison of the definition of the eye and the eye-border in the squatting Owo leopard devouring a human leg (Plate 11) and Benin leopard (Plate 12) further establishes this trait as a clear distinction between Owo and Benin. This characteristic treatment is similar in the animal head held in both hands (Plate 13).

The other noticeable feature of the works of this sub-group is the pervading visible portrayal of emotional content of the figures revealing mood and movement ranging from subtle smile in some, to the glooming and sullen expression or awful and tense look in the others. Each of the heads expresses one feeling or the other.

\section{Conclusion}

The analyses of the Owo terracottas in this study have established Owo as a conglomeration of elements. The diversity of styles as evident in the works has equally confirmed Poynor's (1976:40) descriptions of the art styles of Owo as demonstrating a lack of homogeneity. The popular opinion attributed to this diversity of style however runs contrary to the findings of this study. The emphasis has often been on the "influence of immigrants" as if Owo in the past had always maintained a single pool (or school) of artists, or probably been identified with a particular style, and that the diversity of styles evident in the works are as a result of inspiration or borrowing from the "immigrants" or the neighbouring cultures.

It is here opined that most of the sub-groups (immigrants) that constitute the Owo kingdom must have arrived in the town with their own group of artists and probably when settled, established workshops or arena where each of the group's type and style of art was practiced. If the theory of influence is to be considered, it is certain that most of these groups (if not all) must have influenced each other in one way or the other without a particular group style being considered as "Owo style".

It is very possible that these groups were represented whenever Olowo was to acquire works of art and selection was to be made by Oshogho as earlier noted by Ogunleye in this study. This may probably explain the presence of several hands' in the sculptures of Igbo'laja which is strongly believed to have either been commissioned or collected by Olowo. It is from this point of view that the heterogeneity of styles as demonstrated in Owo terracotta sculptures should be seen.

However, there exist in each particular group, certain distinctive traits that are indeed peculiar to Owo and cannot be found elsewhere even in the neighbouring art traditions, not even in the acknowledged place where such group emigrate. Some good examples of such peculiar groups traits have been identified and analysed in this study as substyles, that is - "the eyes wide apart with sensitively modelled and the well pronounced eye lids" as well as "The wide and enlarged eye having thick upper eye lid without eye lash".

It is however pertinent to note that, despite clearly defined absence of homogeneity and despite the diversity of styles or the significant differences in terms of dates and sizes, there still exist a binder which can be said to be expressed in almost all the terracotta sculptures regardless of styles or sub-styles. This binder is acknowledged by Gillon (1984) who noted that the sculptures are "more vital and vigorous". Owo terracotta sculptures seem to be 'alive' filled with vigour and very dramatic. They generally depict mood and movement. This trait is distinctive of Owo terracotta sculptures and cuts across the sub-styles.

\section{Plates}
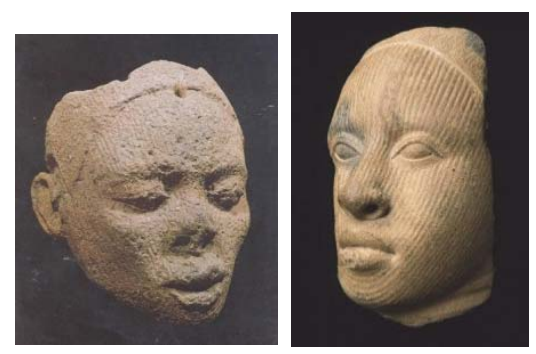

Plate 1: Owo "igbolaja" Plate 2: Ife 

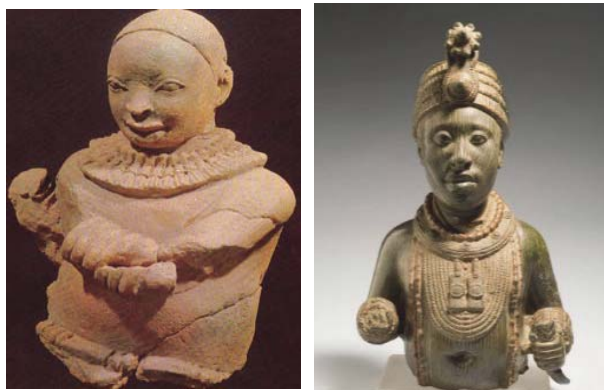

Plate 3: Owo "igbolaja"

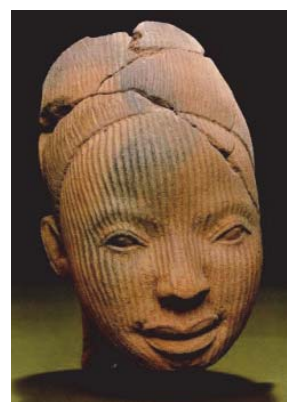

Plate 4: Ife

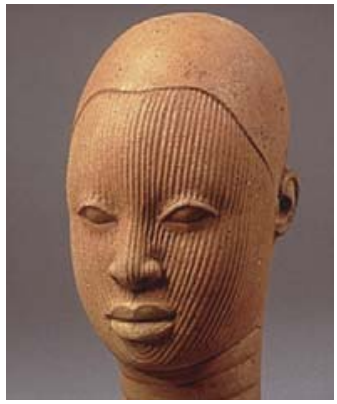

Plate 5: Owo "igbolaja" Plate 6: Ife
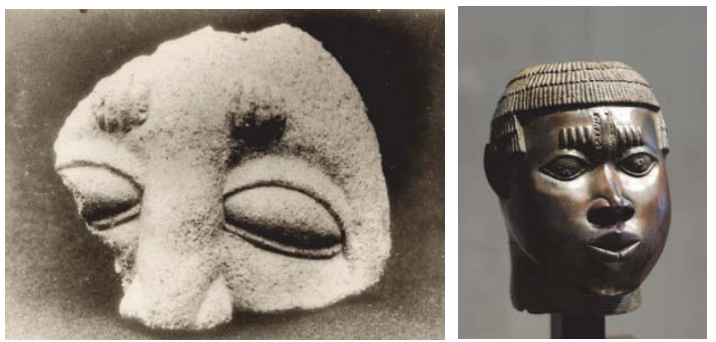

Plate 7: Owo "igbolaja"

Plate 8: Benin
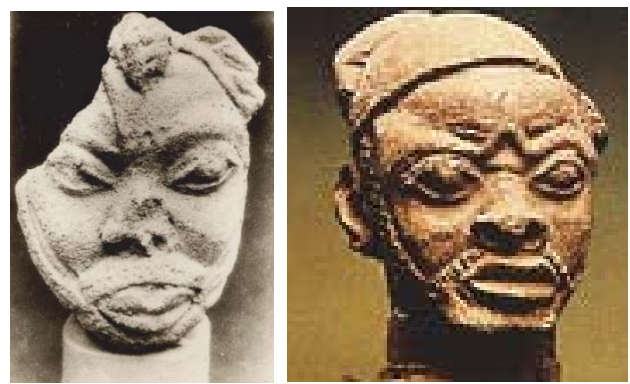

Plate 9: Owo "igbolaja" Plate 10: Owo "igbolaja" 


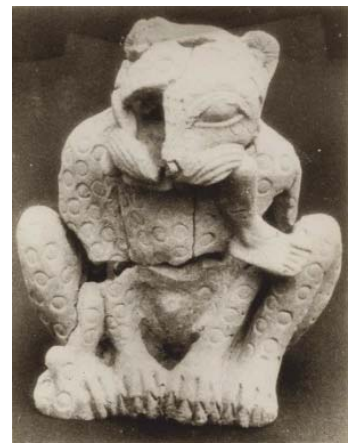

Plate 11: Owo "igbolaja"

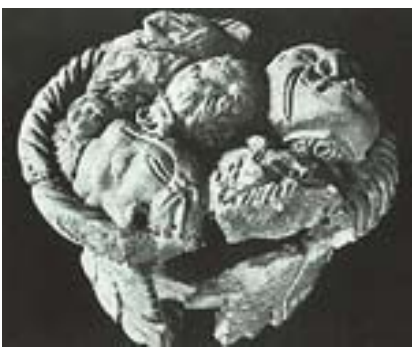

Plate 13: Owo "igbolaja"

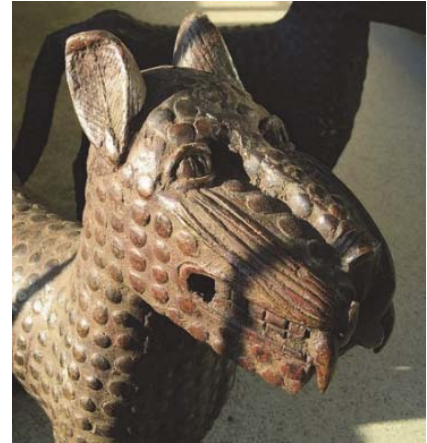

Plate 12: Benin Leopard

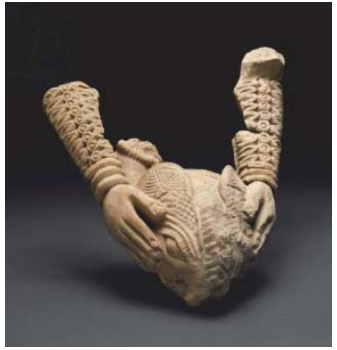

Plate 14: Owo "igbolaja"

\section{Acknowledgments}

Images for analyses in this study were generated from the internet and the following sources:

National Museum Lagos which housed the Igbo'laja finds (Ekpo Eyo's excavation). Upon request, the finds which have been taken off display were brought out by documentation officers of the Museum from the store for my observation, but photographs of the objects were not allowed to be taken.

National Owo Museum which has on display some of the finds of the re-visit of Igbo'laja and few of the Iregun finds. Also on display at the Owo Museum are the enlarged photographs of the Igbo'laja (Ekpo Eyo's) finds. On-the-sport observation was only allowed.

\section{References}

Abiodun Rowland (1989: 103) "The Kingdom of Owo" in Drewal H.J. and Pemberton, John with Abiodun R. Yoruba: Nine Centuries of African Arts and Thoughts.

Adepegba C. O (1984:6) "Introduction" in Peter M. Lukehart. A historical sculpture of West Africa. The Trout Gallery Dickinson College Carlisle, Pennsylvania.

Adepegba C. O. (1995: 18) Nigerian Art: Its Traditions and Modern Tendencies, Jodad Ibadan.

Ashara M.B. (1975:NK) The History of Owo (2nd Edition)

Biebuyck D.P. (1969: 11) "Introduction" in Biebuyck P. Tradition and Creativity in Tribal Arts: University of California Press.

Eyo Ekpo (1976:38) "Igbo'laja Owo" West African Journal of Archaeology, Vol. 6.

Eyo Ekpo (1977:126) Two thousand years of Nigerian Art. Federal Department of Antiquities Lagos

Fatunsin Anthonia (1992:94) Recent Excavation at Owo, Nigerian Heritage, Vol. 1.

Gillon Werner (1984) A short History of African Art Penguin Books.

Douglas Frazer (1975:23) "The Tsoede Bronze and Owo Yoruba" Art, African Arts, Vol. viii (3)

Poynor Robin (1976:40) "Edo influence on the Arts of Owo" African Arts. Vol. ix (4).

Sieber Roy (1969:198) "Comments" in Biebuyck P. Tradition and Creativity in Tribal Arts. University of California Press. 